\title{
New Technique for Medial Patellar Desmotomy in Cattle and Donkeys
}

\author{
Mohamed Wefky El Sherif \\ Department of Animal Surgery, Faculty of Veterinary Medicine, Assiut University, New Valley, Egypt \\ Email: drmwt@hotmail.com
}

How to cite this paper: El Sherif, M.W. (2017) New Technique for Medial Patellar Desmotomy in Cattle and Donkeys. Open Journal of Veterinary Medicine, 7, 144-150. https://doi.org/10.4236/ojvm.2017.710015

Received: September 19, 2017

Accepted: October 27, 2017

Published: October 30, 2017

Copyright $\odot 2017$ by author and Scientific Research Publishing Inc. This work is licensed under the Creative Commons Attribution International License (CC BY 4.0).

http://creativecommons.org/licenses/by/4.0/

\begin{abstract}
The present technique is designed to transect the medial patellar ligament indicated for treatment of upward fixation of patella in cattle and donkeys. A medial patellar desmotomy was performed first on cadavers and then on 21 live cattle or donkeys. In live animals under local anesthesia, a sterile silk strand (USP 1) mounted on a curved needle is inserted through skin at the medial aspect of the medial patellar ligament to the subcutaneous fascia and directed beneath the ligament to emerge at opposite side. The silk is then sawed to cut the ligament. In contrast to other procedures, the desmotomy is less invasive as skin at the surgical site is not incised, pericapsular fat and joint capsules not invaded, and the ligament is fully transected in a one-step procedure. Minimal tissue invasiveness limited infection of surgical site, minimized bleeding, and decreased related postoperative consequences.
\end{abstract}

\section{Keywords}

Patella, Desmotomy, Donkey, Cattle, Upward Fixation

\section{Introduction}

Upward fixation of patella (UFP) has been reported in almost all domestic animals [1] [2] [3] [4] with a higher incidence rate in equine than in cattle [5]. This condition is believed to be due to poor conformation of the hid limb [6]. UFP occurs when the medial patellar ligament (MPL) with its parapatellar fibrocartilage fails to disengage the notch of the medial ridge of the femoral trochlea at the commencement of limb flexion [7]. As a result, the stifle can't be flexed and the hind limb remains extended with a flexed fetlock. The condition may occur temporarily which may spontaneously recover or permanently requiring surgical correction [8]. Affected animals are unable to protract the leg forward, or flex the affected limb causing the involved hind leg to drag behind "Figure 1". Jerky 

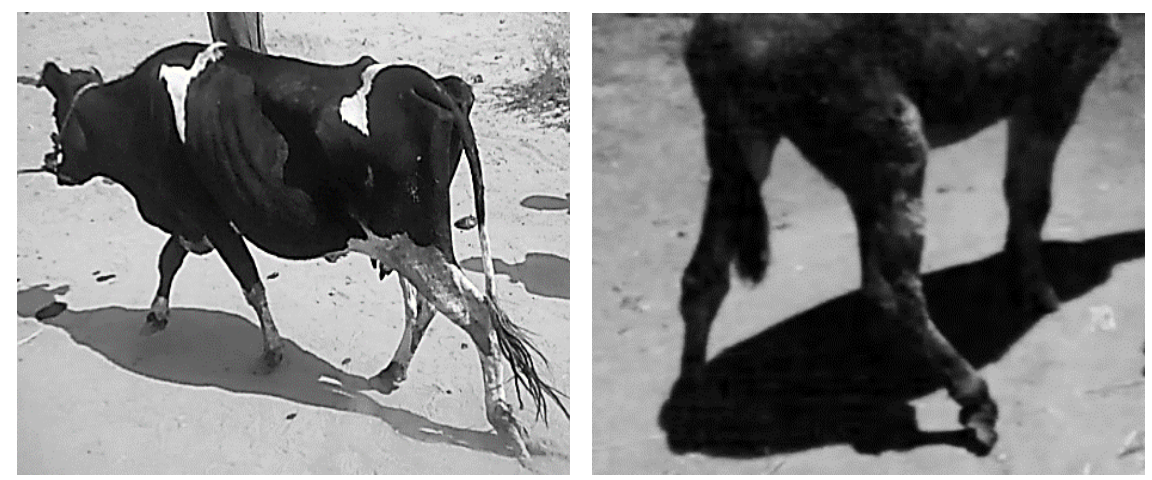

Figure 1. Typical posture of upward fixation of patella in cattle and donkey.

movement is observed at the walk when the MPL and its fibrocartilage disengage from the femoral trochlear ridge [9]. The condition is economically important as it reduces market value of the affected animal especially in riding animals like horses and donkeys.

Several treatment-attempts of upward fixation of patella were reported. Conservative treatment comprises conditioning and rehabilitation exercises with concurrent administration of nonsteroidal anti-inflammatory [9] [10], injection of counter irritants around the middle and medial patellar ligaments [9] and corrective shoeing [11].

Surgical treatment is selected for cases that fail to respond to the conservative treatment. MPL desmotomy (MPLD) and ultrasound-guided medial patellar ligament splitting (MPLS) are surgical options to treat this condition [9] [10] [12] [13] [14] [15]. MPLD is usually performed while the animal is standing and under the effect of light sedation and local anesthesia. Medial patellar ligament ultrasound-guided splitting usually requires general anesthesia and animal positioned in dorsal recumbency. MPLD is a relatively invasive surgical treatment as it requires a $5 \mathrm{~cm}$ skin incision. The MPLS performed with or without ultrasound-guidance requires multiple small skin incisions. Short and long term post-operative complications associated with these surgical treatments include swelling, pain, sever bleeding, wound infection, persistent low-grade lameness and persistence of UPF signs due to incomplete transection of the medial patellar ligament [7] [16] [17] [18]. Gibson et al., 1989 [19], reported that, medial patellar desmotomy results in pathologic changes in the articular cartilage of the patella and adjacent soft tissues. The present study presents a new surgical technique for upward fixation of patella in cattle and donkeys which is thought to be minimal invasive, easy and more suitable for field conditions.

\section{Materials and Methods}

The study was approved by the animal welfare committee of the faculty of veterinary medicine, New Valley, Egypt. Ref. No. 1/2016.

Surgical anatomy of the stifle was performed on donkey cadaver without and after insertion of silk suture behind the medial tibiopatellar ligament "Figure 2". 


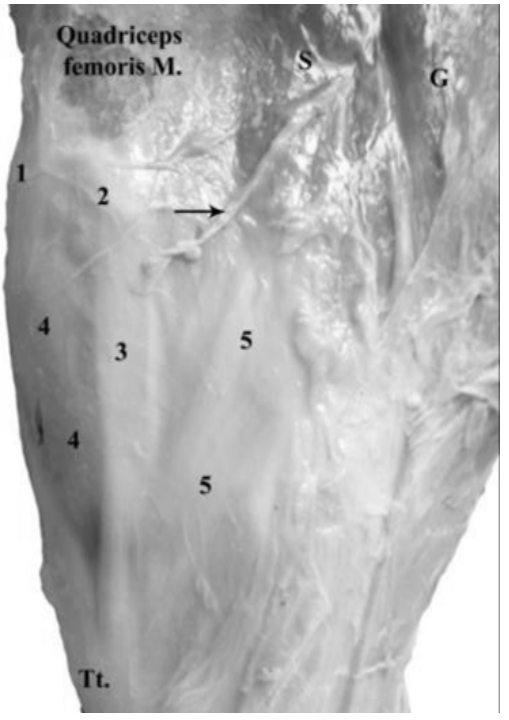

(a)

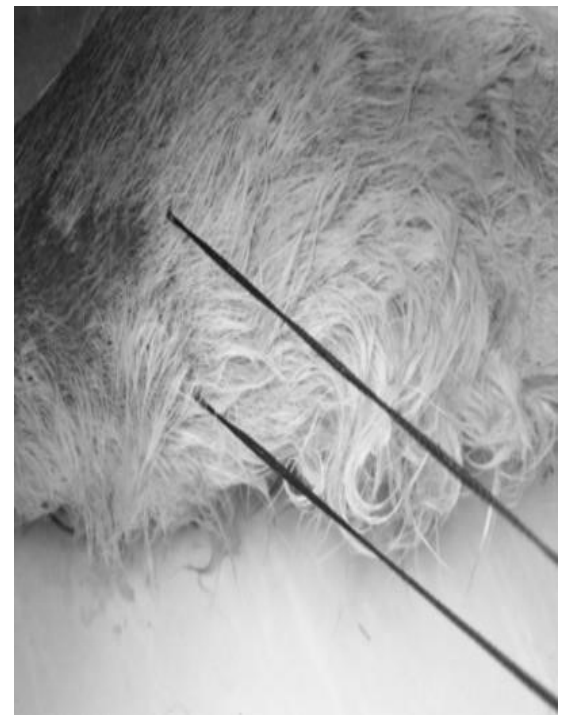

(b)

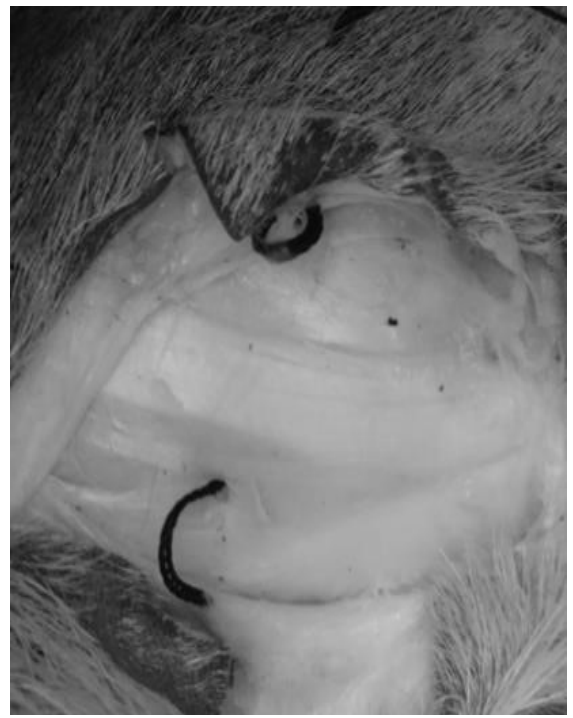

(c)

Figure 2. Surgical anatomy of stifle on a cadaver. (a) superficial anatomy of stifle (1, patella; 2, parapatellar cartilage; 3 , medial patellar ligament; 4, patellar retinacula; 5 , insertion of the common tendon of sertorous (S) and gracillis muscles $(\mathrm{G})$ and $\mathrm{Tt}$, tibial tuberosity), (b) insertion of silk beneath the medial patellar ligament, (c) dissection to assess the course of the silk strand.

Five donkeys (four males and one female, aged 5 - 9 years and weighing 190 $230 \mathrm{~kg}$ ) and eight cows (aged 2 - 6 years and weighting $350-450 \mathrm{~kg}$ ) were admitted to the mobile surgery clinic of the faculty of veterinary medicine, New valley, Egypt, (2014-2016). They were diagnosed with permanent upward fixation of the patella.

The donkeys and cows were sedated with xylazineHCl (Xylaject, ADWIA pharma, Egypt), (1 mg/kg and $0.1 \mathrm{mg} / \mathrm{kg}$ ) administered intravenously. The donkeys were secured with tying the front feet with ropes and kept in standing position while cows were positioned in lateral recumbency with the affected limb up. The stifle region of the operated limb was clipped and disinfected with absolute alcohol wipes followed by application of povidone iodine $10 \%$ solution (Betadine, Mondio, Switzerland). Ten milliliters of lidocaine Hcl 2\% (Depocaine, Depiky pharma, Egypt) was injected underneath the skin and deep between the middle and medial patellar ligaments, about $2 \mathrm{~cm}$ above the tibial plateau. Further disinfection was performed with alcohol wipes and povidone iodine solution. The medial patellar ligament was located with its insertion to the tibial tuberosity then held with the tips of thumb and index fingers. Skin was not incised. Instrument needed are half circle reverse cutting needle \#3, needle driver and silk strand (USP 1) in an appropriate length. Using aseptic technique, a sterile strand of silk (USP 1) mounted on a half circle reverse cutting needle \#3 is inserted through skin $2 \mathrm{~cm}$ above the tibial crest at the medial aspect of the medial patellar ligament (at the tip of finger) and directed underneath the ligament to emerge on the opposite side (at the tip of the other finger) between the middle and medial patellar ligaments. The two ends of the silk strand were grasped with both hands and were used to transect the ligament with sawing ac- 
tion movements. The sawing action was discontinued when a "POP" sound was noted, indicating completion of the desmotomy. The silk strand was then removed and surgical site disinfected again with povidone iodine solution "Figure 3".

Daily wound care with application of $10 \%$ povidone iodine antiseptic solution to the site of the procedure was performed for five successive days after surgery. Stable rest for 6 weeks was recommended. The surgical time (the time between the needle insertion and removal of silk strand from the surgical site) for each procedure was recorded. Post-operative assessment was based on daily examination of animals for lameness signs, presence of gross signs of inflammation such as "swelling, hotness, pain and redness".

\section{Results}

The pilot anatomical study revealed the optimal site for the needle insertion was at the cranial aspect of the stifle, three fingers proximal to tibial tuberosity. This site was found to be safe due to presence of periarticular fat while, proximal to this point, it is possible to damage the superficial branch of the saphenous nerve or to penetrate the medial extension of the femoro-patellar joint capsule.

The surgical procedure was technically easy to perform and no intra-operative complications were recorded. The mean surgery time \pm SD was $3.89 \pm 1.45 \mathrm{mi}-$ nutes.

Minor bleeding was noted at the points of needle insertion and exit point which stopped spontaneously. "POP" sound was heard in all cases and indicated complete transection of tensed medial patellar ligament. All treated animals regain normal posture and were able to walk normally immediately after the procedure.

No post-operative complications were recorded over two months after the procedures in any of the treated animals. Daily examination of the animals in rest and motion revealed no signs of lameness. Minor, unnoticed scar points

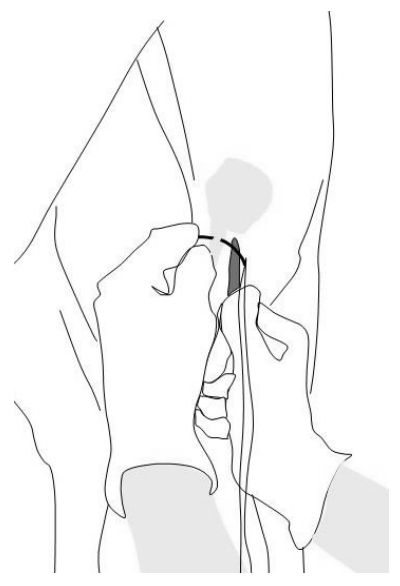

(a)

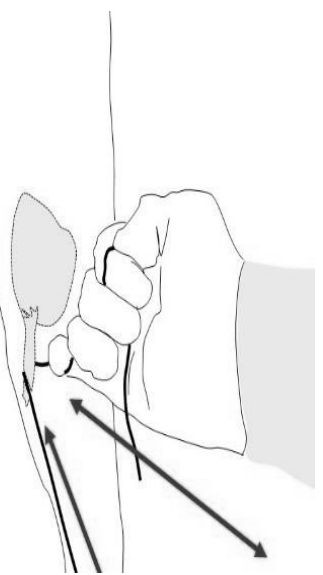

(b)

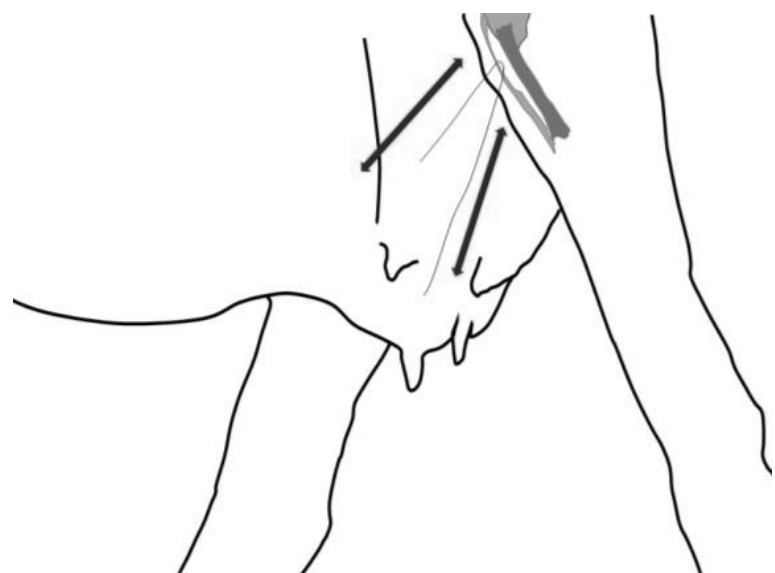

Figure 3. The surgical procedure (in donkeys at the left and in cattle at the right). 
were present at the points of insertion and exit of the surgical needle. Signs of mild inflammation "mild swelling and redness" was noticed in one cow which subsides at the second day of the operation. Stifle of the treated animals was normal on manual palpation except for limited tissue movability which may indicate fibrosis.

\section{Discussion}

The procedure presented here is a new minimal medial patellar desmotomy technique. It was performed successively and described in cattle and donkeys. Open and closed medial patellar ligament desmotomy described by [5] [7] [12] [16] [17] [18] [20] are the most common performed techniques for treatment of UFP condition in large animals. Closed technique involves stab skin incision and introduction a Bard Parker blade underneath the medial patellar ligament in order to sever it. The open technique is more tissue invasive and involves larger skin incision, exposure of the MPL and application of stitches to close the wound. The advantage of the present desmotomy approach is the absence of skin incision, limited amount of surgical instrumentation needed and speed of execution.

Another technique which is the ultrasound-guided MPL splitting described by [7] [21] is more sophisticated and involves performing under general anesthesia, skin incision and splitting the MPL with Bard Parker blade directly visualized with ultrasound. The present technique was easily performed in the field, performed in standing or lateral recumbent positions with minimal physical or chemical securing, didn't require special instruments and performed under local anesthesia.

Incomplete severing of the ligament is a common intra-operative complication of the blind or closed technique [16], which necessitates several attempts to sever the ligament completely. The results of present technique showed complete transection of the medial patellar ligament in all treated animals. Bleeding, infection and swelling are common post-operative complications referred to skin incision and tissue invasion [1] [5] [6]. The present approach was minimal tissue invasive and the subsequent bleeding, infection and swelling were not noticed. The short term gross examination of treated animals showed immediate return of stifle function and absence of post-operative inflammatory signs.

\section{Conclusion}

Placing the animal in lateral recumbency is a disadvantage but it was recommended in order to avoid sudden movement of the animal during the procedure. The presented technique was found to be easy, time and money saving, field applicable, accurate and associated with minor post-operative complications. Further long-term study is required to evaluate this technique with the aid of more advanced diagnostic methods and tools. 


\section{Acknowledgements}

My sincere thanks and appreciation to Professors, head and staff members of surgery department, Assiut University for their continuous support.

\section{References}

[1] Shettko, D.L. and Trostle, S.S. (2000) Diagnosis and Surgical Repair of Patellar Luxation in a Flock of Sheep. Journal of the American Veterinary Medical Association, 216, 564-66. https://doi.org/10.2460/javma.2000.216.564

[2] Di Dona, F. Della Valle, G., Balestriere, C., Lamagna, B., Meomartino, L., Napoleone, G., Lamagna F. and Fatone, G. (2016) Lateral Patellar Luxation in Nine Small Breed Dogs. Open Veterinary Journal, 6, 255-258. https://doi.org/10.4314/ovj.v6i3.16

[3] Duzgune, O. (2005) A Retrospective Study: Evaluation of Patellar Luxation Cases of Cats. Turkish Journal of Veterinary and Animal Sciences, 20, 279-83.

[4] Araujo, J.A.S., Curcio, B., Alda, J., Medeiros, R.M.T. and Riet-Correa, F. (2008) String Halt in Brazilian Horses Caused by Hypochaerisradicata. Toxicon, 52, 190-193. https://doi.org/10.1016/j.toxicon.2008.04.164

[5] Hanson, R.R. and Peyton, L.C. (1987) Surgical Correction of Intermittent Upward Fixation of Patella in a Barhman cow. Canadian Veterinary Journal, 28, 675-677.

[6] Stick, A.A. (2006) Stifle, in Aur and Stick Editors, Equine Surgery. 3rd Edition, Saunders Elsevier, New York, 1325-1326.

[7] Tnibar, M.A. (2002) Medial Patellar Ligament Splitting for Treatment of Upward Fixation of the Patella in 7 Equines. Veterinary Surgery, 31, 462-467.

https://doi.org/10.1053/jvet.2002.34660

[8] Lacorix, J.V. (2005) Luxation of Patella. In: Lacorix, J.V., Lameness of the Horse, Kashvet E-learning, New York, 186171.

[9] Brooks, J.H. (2007) Intermittent Upward Fixation of Patella in the Horse: A Literature Review.

[10] Stashak, T.S. (2002) Upward Patellar Fixation. In: Adam's Lameness in Horse, 5th Edition, Lippincott, Williams and Wilkins, New York, 737-741.

[11] Maggie, P., Koontz, Z.D., Lynch, T.M., Hughes, F.E. and Slone, D.E. (2015) Outcome of Medial Patellar Ligament Desmoplasty for Treatment of Intermittent Upward Fixation of the Patella in 24 Horses (2005-2012). Canadian Veterinary Journal, 56, 193-195.

[12] Turner, A.S. and Mcllwraith, C.W. (1989) Medial Patellar Desmotomy. In: Techniques in Large Animal Surgery, 2nd Edition, Lea and Febiger, Philadelphia, 133-135.

[13] Chandrapurial, V.P., Bhadauria, P. and Jadoun, Y.S. (2012) Upward Fixation of Patella and its Clinical Management in Large Ruminants. Intas Polivet, 13, 259-261.

[14] Madhul, D.N., Monsang, S.W., Singh, J. and Pawde, A.M. (2012) Bilateral Medial patellar Desmotomy in a Colt. Intas Polivet, 13, 264-266.

[15] Singh, A.K., Gangwar, A.K., Devi, Kh.S. and Singh, H.N. (2015) Studies on Incidence and Evaluation of the Closed Medial Patellar Desmotomy in Lateral Recumbency in Bovines. Veterinary World, 15, 221-224. https://doi.org/10.14202/vetworld.2015.221-224

[16] Ramakrishna, O. (1972) Comparative Studies on Treatment of Chronic Subluxation of the Patella in Buffaloes. Indian Veterinary Journal, 49, 1150-1153. 
[17] Sharma, S.P. (1980) Medial Patellar Desmotomy as Treatment of Stringhalt in Ponies. Indian Veterinary Journal, 57, 684-685.

[18] Ali, M.A. and Hashim, M.A. (1984) Upward Fixation of Patella in Cattle. Bangladesh Veterinary Journal, 18, 69-70.

[19] Gibson, K.T., McIlwraith, C.W., Park, R.D. and Norrdin, R.W. (1989) Production of Patellar Lesions by Medial Patellar Desmotomy in Normal Horses. Veterinary Surgery, 18, 466-471. https://doi.org/10.1111/j.1532-950X.1990.tb01128.x

[20] Naveen, M., Kumar, D.D., Shivaprakash, B.V., Usturge, S.M., Pawar, A. and Patil, N.A. (2013) Comparison of Different Methods of Medial Patellar Desmotomy in Bovines. Indian Journal of Veterinary Surgery, 34, 94-96.

[21] Andersen, C. and Tnibar, A. (2016) Medial Patellar Ligament Splitting in Horses with Upward Fixation of the Patella: A Long-Term Follow-Up. Equine Veterinary Journal, 48, 312-314. https://doi.org/10.1111/evj.12435 